\title{
MAGNETIC RESONANCE ENTEROGRAPHY (MRE) FOR PREDICTING THE CLINICAL COURSE OF CROHN'S DISEASE STRICTURES
}

\author{
Julien D Schulberg ${ }^{1,2}$ \\ Gastroenterologist \\ Emily K Wright ${ }^{1}$ \\ Gastroenterologist \\ Bronte A Holt
Gastroenterologist \\ Tom R Sutherland ${ }^{2,3}$ \\ Consultant Radiologist
}

Simon J Hume ${ }^{1}$

Medical Resident

Amy L Hamilton ${ }^{1,2}$

Clinical scientist

Alyson L Ross
Research Nurse
William C Connell ${ }^{1,2}$
Associate Professor of Gastroenterology

Steven J Brown ${ }^{1}$

Gastroenterologist

Mark Lust ${ }^{1}$

Gastroenterologist

Ashley M Miller ${ }^{1}$

Gastroenterologist

Sally J Bell ${ }^{1,2}$

Associate Professor of Gastroenterology

Michael A Kamm ${ }^{1,2}$

Professor of Gastroenterology

This is the author manuscript accepted for publication and has undergone full peer review but

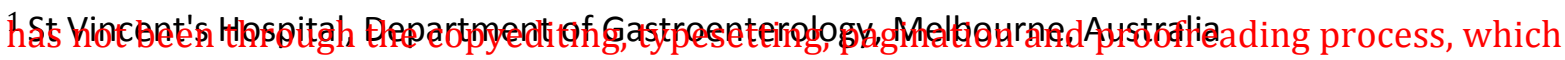

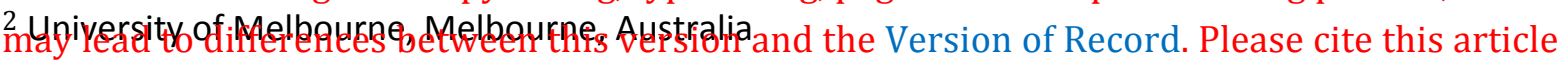
3 Styincent's Hospital Mgedgourne, Department of Medical Imaging, Australia

This article is protected by copyright. All rights reserved. 


\title{
AFFILIATIONS:
}

Departments of Gastroenterology and Radiology, St Vincent's Hospital, Melbourne, Australia University of Melbourne, Melbourne, Australia

CONFLICTS OF INTEREST: No author has any conflict of interest.

AUTHOR CONTRIBUTIONS: JDS, MAK, EKW and BAH - study concept and design. JDS, SJH - acquisition of data. JDS - statistical analysis. TRS - MRE analysis. All authors - data interpretation; drafting of the manuscript; critical review of the manuscript for important intellectual content.

\section{Keywords:}

Crohn's Disease, Inflammatory Bowel Disease, Stricture, Stenosis, Magnetic Resonance Enterography (MRE), Endoscopic balloon dilatation

\author{
Author for Correspondence: \\ Dr Emily Wright \\ St Vincent's Hospital \\ Victoria Parade \\ Fitzroy 3065 \\ Melbourne \\ Australia \\ Tel: + 61392312211 \\ Fax: + 61392313580 \\ E: Emily.Wright@svha.org.au
}

\section{Acknowledgements:}

The National Health and Medical Research Council (NHMRC) supported JDS and BAH. GESA /Ferring IBD Clinician Establishment Award supported EKW. Australasian Gastro Intestinal Research Foundation (AGIRF), AbbVie and the Spotlight Foundation supported the Project 


\begin{abstract}
Background and aims: Strictures are the commonest Crohn's disease complication but their natural history is unknown. This study aimed to characterise inflammation, predict prognosis, and understand the impact of drug therapy using Magnetic Resonance Enterography (MRE).

Methods: Patients with a stricture diagnosed on MRE over a 5-year period were reviewed for MRE disease extent and inflammation, clinical course, C-Reactive Protein (CRP), response to anti-TNF therapy, endoscopic dilatation, hospitalization and surgery.
\end{abstract}

Results: 136 patients had 235 (77 one and $59 \geq$ two) strictures. Treatment: $46 \%$ of patients underwent surgery after a median 6 months; median follow-up for those not requiring surgery was 41 months. Predictors of surgery: Hospitalization due to obstruction predicted subsequent surgery (OR 2.50; $95 \% \mathrm{Cl} 1.06-5.90)$ while anti-TNF therapy commenced at stricture diagnosis was associated with a reduced risk (OR 0.23; 95\% $\mathrm{Cl} 0.05-0.99$ ). MRE characteristics associated with surgery were proximal bowel dilatation $\geq 30 \mathrm{~mm}$ diameter (OR, 2.98; $95 \% \mathrm{Cl} 1.36-6.55)$, stricture bowel wall thickness $\geq 10 \mathrm{~mm}$ (OR 2.42; 95\% Cl 1.11-5.27), and stricture length $>5 \mathrm{~cm}$ (OR 2.56; $95 \% \mathrm{Cl} 1.21-5.43$ ). $81 \%$ of patients with these 3 adverse MRE features required surgery versus $17 \%$ if none were present $(P<0.001)$. Accuracy for these 3 MRE variables predicting surgery was high (AUC 0.76).

Conclusion: MRE findings in Crohn's disease strictures are highly predictive of the disease course and the need for future surgery. MRE may also identify who would benefit from treatment intensification. Anti-TNF therapy is associated with reduced risk of surgery and appears to alter the natural history of this complication.

\title{
INTRODUCTION
}

Strictures are the most common complication of Crohn's disease.(1) (2) At diagnosis 10 to 28 percent of patients have strictures(1) and by five years one third will have stricturing disease.(1) Fifty percent of Crohn's disease patients require surgery within ten years of diagnosis(2), with stricturing disease being the most common indication. No drug therapy has been proven in randomized trials to influence

This article is protected by copyright. All rights reserved. 
the course of stricturing disease or prevent surgery, but anti-tumour necrosis factor (TNF) therapy may delay or prevent the need for surgery.(3-5)

Cross sectional imaging is increasingly used to assess Crohn's disease extent and severity. Magnetic resonance enterography (MRE) is safe and highly accurate for the evaluation of Crohn's disease and its complications.(6) MRE is the preferred modality for the diagnosis of Crohn's strictures with high sensitivity and specificity for stricture diagnosis of $55-100 \%$ and $91-100 \%$ respectively.(7)

Only one study, the 'Efficacy of Adalimumab in Patients with Crohn's Disease and Symptomatic Small Bowel Stricture (CREOLE)' Study has evaluated the role of MRE in predicting the outcome of patients with Crohn's disease related strictures.(3) Ninety seven patients with Crohn's disease symptomatic small bowel strictures were treated with standard dose adalimumab. Sixty-two patients (64\%) achieved "treatment success" at week 24, avoiding surgery or endoscopic dilatation. That study showed that a shorter stricture length, absence of pre-stenotic small bowel dilatation, and absence of a stricture-associated fistula were associated with treatment success with adalimumab.(3) The authors developed a risk score incorporating both MRE and clinical features predicting short term response to anti-TNF treatment, but not surgical risk.

The current study aimed to determine whether clinical and MRE Crohn's disease features can predict the clinical course of strictures, including the occurrence of surgery. A secondary aim was to examine the impact of anti-TNF therapy introduced at the time of stricture diagnosis. This large, wellcharacterised cohort had their disease course assessed from the time of MRE stricture diagnosis.

\section{METHODS}

All patients diagnosed with a Crohn's disease-associated stricture on MRE over a five-year period were included. The radiology and clinical databases of a large inflammatory bowel disease unit in a specialist hospital were used to identify patients diagnosed with strictures between January 2011 and March 2016. Patients without a minimum 12 months follow up (if no stricture surgery) and those with an incomplete medical record were excluded from analysis. Where a patient had more than one MRE performed, the MRE which first identified a stricture was used for analysis.

Hospital records were reviewed by two independent investigators (JDS and SJH). Crohn's disease was confirmed by standard endoscopic, histological and radiological criteria.

This article is protected by copyright. All rights reserved. 
Study data were collected and managed using REDCap, an electronic data capture tool hosted at the University of Melbourne, Australia.(8)

Patients' demographic data, disease location and behavior, Montreal classification(9), clinical history, smoking status at the time of stricture diagnosis, previous Crohn's disease surgery, symptoms, endoscopic findings, C-reactive protein (CRP), IBD medications at time of diagnosis and within the next 3 months, surgical intervention after stricture diagnosis, and endoscopic dilatations were recorded. Crohn's Disease Activity Index (CDAI) data were not available for analysis.

MRE scans were reviewed by a single radiologist (TRS) specialising in inflammatory bowel disease imaging. The radiologist was blinded to the patients' clinical data, other imaging and future treatment decisions including surgery.

All MRE examinations were performed on one of two 1.5T Siemens scanners (Avanto and Symphony, Siemens AG, Erlangen Germany) following an 8 hour fast and the ingestion of $1500 \mathrm{~mL}$ sorbitol. Routine images included a coronal T2 free inversion with steady state precession (FISP), half Fourier turbo spin echo (HASTE) as a coronal and axial, and pre-contrast fat saturated T1 volumentric interpolated breath-hold examination (VIBE). The patient then had an intravenous injection of $20 \mathrm{mg}$ hyoscine butylbromide, unless contraindicated, followed by intravenous injection of $7.5 \mathrm{~mL}$ Gadovist (Bayer Schering Pharma, Germany) and $10 \mathrm{~mL}$ saline flush with a further coronal fat saturated T1 (VIBE) acquired 70 seconds later. Coronal diffusion weighted images were obtained with b values of 50,400 and 800 from which an ADC map was calculated.

All of the following criteria had to be present to diagnose a stricture:

- $\geq 80 \%$ luminal reduction compared to proximal bowel

- bowel wall thickness $>3 \mathrm{~mm}$

- narrowing present on all MRE acquisitions

Stricture MRE features recorded included: maximum bowel wall thickness, stricture length, minimum luminal diameter $(\mathrm{mm})$, stricture ulceration, immediate and delayed stricture enhancement, strictureassociated edema, proximal luminal diameter, number of strictures, sum length of all strictures, mesenteric fat inflammation, diffusion weighted imaging (DWI) hyper-intensity to assess inflammation, relative contrast enhancement, Magnetic Resonance Index of Activity (MaRIA) score(10), and associated internal fistulas, abscesses and tissue phlegmons. DWI hyperintensity was present if the DWI signal of the diseased bowel wall segment was higher than that of the normal bowel wall.

This article is protected by copyright. All rights reserved. 
When multiple strictures were present, the radiologist selected a dominant stricture based on the greatest wall thickness, narrowest lumen, and the greatest difference between the luminal and prestenotic caliber.

The decision for surgery, endoscopic therapy and drug therapy were determined by the treating physician based on the clinical situation. Most patients and decision-making were discussed at an inflammatory bowel disease multidisciplinary meeting.

The primary outcome was the rate of stricture surgery in relation to MRE characteristics. Patient characteristics, and the effects of drug and endoscopic therapy on the clinical course of strictures were secondary outcomes.

\section{Statistical Analysis}

Statistical analysis was performed using STATA Version 15.1 (StataCorp LLC, College Station, USA). Continuous variables were analyzed using parametric and non-parametric testing as appropriate. Categorical variables were described as percentages. Univariate analysis was performed using chisquare test, Fisher's exact test, student $t$ test and binary logistic regression to evaluate the distribution of categorical and continuous variables describing patient demographics, clinical and MRE features. A two-tailed $p$-value $<0.05$ was considered as statistically significant. Variables with a $p$-value $<0.10$ were used in a multivariable regression analysis. Receiver operator characteristic (ROC) curves were used to determine cut-off values for continuous variables. Multivariable logistic regression was performed to determine which MRE clinical features were associated with an increased risk for stricture surgery. Results of the multivariate analyses are presented as odds ratios (OR) with $95 \%$ confidence interval $(\mathrm{Cl})$. Sensitivity and specificity analysis were performed on features that were significant on the multivariable analysis.

The MRE risk stratification score comprised features that were significant in the multivariable logistic regression. As odd ratios were all between 2.5 and 3, a simple risk score with the same weight for all variables was chosen for simplicity. Kaplan-Meier survival analysis was performed for evaluation of surgery free survival based on the risk stratification model and proportional hazard assumptions were tested.

\section{Ethical Considerations}

This article is protected by copyright. All rights reserved. 
Ethical approval was granted by the Human Research Ethics Committee (HREC) of St Vincent's Hospital, Melbourne, Australia (HREC 022 /17).

\section{RESULTS}

\section{Patient Demographics}

Four hundred and ninety-three MRE scans were identified with the keyword of 'stricture' or 'stenosis' from the hospital MRI database within the 5-year search period (Figure 1). Eight additional patients with an MRE stricture were identified from hospital clinical and endoscopy databases. Two hundred and eighty-three scans were removed as the MRE report stated that there was 'no' stricture or stenosis. Thirty-six patients had two or more MRE scans (44 scans total) within the time period. The MRE which first diagnosed the stricture was used for this analysis, as this was felt to most accurately represent the time closest to stricture diagnosis and allowed for an accurate analysis of the natural history of this disease complication. Thirty-eight patients who did not have Crohn's disease, had incomplete records, or had $<12$ months follow up were excluded. One hundred and thirty-six patients with 235 strictures were therefore included in this study.

Demographic details for included patients are shown in Table 1. Sixty-one (45\%) patients were male, with a median age at stricture diagnosis of 40 (IQR 29-48). Most patients (90\%) were diagnosed with Crohn's disease below the age of 40 . Over half (53\%) had ileo-colonic disease. One hundred and fourteen (84\%) had isolated stricturing (B2) disease. Ninety (66\%) had previous Crohn's disease surgery a median of 8 (IQR 4-13) years prior to presentation with the current stricture.

Thirty-nine (29\%) patients were hospitalized due to bowel obstruction in the 3 months before or the 3 months after their stricture-diagnosing MRE. At the time of MRE stricture diagnosis 38 (28\%) patients were on anti-TNF therapy, $92(68 \%)$ were on an oral immunomodulator and $41(30 \%)$ were taking corticosteroids. Twenty-three (17\%) patients were on no Crohn's disease treatment.

\section{Outcome and Stricture Surgery}

Sixty-three (46\%) patients had stricture surgery during follow up, after a median of 6 months (IQR 2-11 months). Of those who had stricture surgery, 13 of the 63 (21\%) had surgery within 60 days of MRE stricture diagnosis and 48 (76\%) within 12 months. Sixty-one (97\%) patients had an intestinal resection with or without additional strictureplasties, one patient had an isolated strictureplasty, and one patient had a diverting ileostomy.

This article is protected by copyright. All rights reserved. 
Seventy patients (51\%) underwent diagnostic endoscopy within six months of their MRE. The stricture was reached in $51(73 \%)$ patients. Of these $19(37 \%)$ of strictures were passable endoscopically and 32 (63\%) were non-passable. More patients with endoscopically passable strictures subsequently avoided surgery when compared to those with impassable strictures, although this difference was not statistically significant $(P=0.06)$. Thirty-two patients underwent endoscopic balloon dilatation. The endoscope was able to pass the stricture(s) after dilatation in $22(69 \%)$ patients. Failure to pass the endoscope through the stricture after dilatation was associated with a significantly higher risk of surgery (OR 5.92; 95\% Cl 1.05-33.43).

Median follow-up for those not requiring surgery was 41 months (IQR 26-56 months).

Three patients died during the follow up period: one from amyloidosis, one from sepsis and alcoholic cirrhosis, and one from suicide following the formation of an ileostomy and the diagnosis of cancer within the resected stricture. No other intestinal cancers were diagnosed in this cohort.

\section{Clinical Predictors for Stricture Surgery}

Two thirds of patients had previously undergone a bowel resection for Crohn's Disease. Prior resection was associated with a lower risk of stricture surgery in the current cohort. Thirty six of 91 (40\%) patients who had previous resection had repeat surgery (usually for anastomotic strictures) versus 27 of $45(60 \%)$ patients without previous surgery who had surgery for de novo strictures (OR $0.44 ; 95 \% \mathrm{Cl}$ $0.21-0.91)$.

A CRP $\geq 10 \mathrm{mg} / \mathrm{L}$ at stricture diagnosis was associated with an increased risk of having surgery: 27 of 34 (79\%) with CRP $\geq 10 \mathrm{mg} / \mathrm{L}$ versus 27 of 73 (37\%) with a CRP <10mg/L (OR 2.71; 95\% Cl 1.25-5.85).

Hospitalization due to bowel obstruction within three months before or after stricture diagnosis was associated with an increased risk of having surgery: 23 of 39 (59\%) hospitalized vs 40 of 97 (41\%) not hospitalized (OR $2.05 ; 95 \% \mathrm{Cl} 0.96-4.36)$. This difference was not statistically significant on univariable analysis, but was on multivariable analysis (see below). No standardized assessment of patients' symptom duration and intensity of obstructive symptoms were available.

Further clinical associations are shown in table 2. 
Baseline drug therapy was not associated with avoidance of subsequent stricture surgery. This included anti-TNF therapy. However newly commenced anti-TNF therapy within three months of stricture diagnosis was associated with a reduced risk of future surgery.

Three of $14(21 \%)$ patients who newly commenced anti-TNF therapy had surgery compared to 60 of $122(49 \%)$ who did not receive anti-TNF therapy $(\mathrm{P}=0.049)$. This remained significant on multivariable logistic regression analysis (OR $0.23 ; 95 \% \mathrm{Cl}, 0.05-0.99)$. No other new drug therapy following stricture diagnosis was associated with prevention of stricture surgery (Table 2).

\section{MRE Characteristics and the Need for Stricture Surgery:}

Seventy-seven patients (57\%) had one stricture identified on MRE and 59 (43\%) had $\geq 2$ strictures with 3 patients having more than 5 strictures (Table 3). An example MRE image is shown in Figure 2 . The single or dominant stricture was easily identifiable on the MRE in 104 (76\%) of patients, but required application of the above criteria in the remainder. In 77 (57\%) patients the dominant stricture was a de novo small bowel stricture. Forty-five (33\%) had a dominant anastomotic stricture (nearly all ileocolonic (91\%)), and in $14(10 \%)$ it was a colonic stricture (Table 4). Four patients (3\%) had a dominant jejunal stricture and none had a duodenal stricture. There was no association between stricture location and the occurrence of surgery.

Median maximum wall thickness on MRE at the site of the stricture was 9mm [IQR 7-12mm]. Bowel wall thickness at the stricture was strongly associated with surgery $(P=0.001)$. Stricture wall thickness of $\geq 10 \mathrm{~mm}$ was associated with an almost three times increased risk of surgery (OR $2.78 ; 95 \% \mathrm{Cl}, 1.34$ 5.74). Dominant stricture length was also strongly associated with surgery $(P=0.001)$. Stricture length of $>5 \mathrm{~cm}$ was associated with a more than three times increased risk of surgery (OR $3.26 ; 95 \% \mathrm{Cl}, 1.61$ 6.62). Strictures associated with proximal bowel dilatation of $\geq 30 \mathrm{~mm}$ highly predicted the need for surgery, (OR, $3.11 ; 95 \% \mathrm{Cl}, 1.49-6.52)$, with $76 \%$ of these patients having surgery.

A number of additional MRE features of active bowel inflammation were associated with surgery. This included oedema associated with the stricture (OR, 3.10; $95 \% \mathrm{Cl}, 1.52-6.29)$, stricture ulceration (OR, $1.87 ; 95 \% \mathrm{Cl}, 0.94-3.71)$, inflammatory changes in the mesenteric fat (OR, 3.10; 95\% Cl, 1.54-6.26) and DWI hyperintensity $(\mathrm{OR}, 2.70 ; 95 \% \mathrm{Cl}, 1.39-5.26)$. Relative contrast enhancement was not associated with surgery.

This article is protected by copyright. All rights reserved. 
A fistula in association with a stricture was seen in 20 patients (15\%) and was associated with an increased risk of surgery $(\mathrm{OR}, 3.19 ; 95 \% \mathrm{Cl}, 1.14-8.89)$ whilst the presence of an MRE abscess or phlegmon, seen in 23 patients (17\%), was not (OR 1.64; Cl, 0.66-4.05).

The MaRIA score was highly predictive of the occurrence of surgery. A score of $\geq 24$ was associated with more than three times increased risk of surgery [OR of $3.59(95 \% \mathrm{Cl}, 1.73-7.47)]$ compared to a score $<24$.

\section{Multivariable Logistic Regression Analysis and Risk Stratification Based on MRE Characteristics}

Multivariable analysis was performed incorporating factors on univariate analysis with a $\mathrm{P}$ value $<0.10$. MRE characteristics associated with increased risk for bowel surgery were proximal bowel dilatation $\geq 30 \mathrm{~mm}$ diameter (OR, 2.98; $95 \% \mathrm{Cl}, 1.36-6.55)$, bowel wall thickness (BWT) at stricture $\geq 10 \mathrm{~mm}$ (OR, 2.42; 95\% Cl, 1.11-5.27), and stricture length $>5 \mathrm{~cm}(\mathrm{OR}, 2.56 ; 95 \% \mathrm{Cl}, 1.21-5.43)$ (Table 5). On Receiver Operator Curve (ROC) analysis, these three MRE variables combined could predict future surgery with good accuracy (AUC 0.76). When hospitalization was added to the three MRE variables the AUC was 0.78. Sensitivity and specificity analysis were performed for these MRE characteristics and stricture surgery (Table 5). Of the three MRE characteristics considered individually, proximal bowel dilatation $\geq 30 \mathrm{~mm}$ had the highest sensitivity (76\%) whilst stricture bowel wall thickness $\geq 10 \mathrm{~mm}$ had the highest specificity (75\%). When combing these three MRE characteristics there was a $95 \%$ specificity for stricture surgery with a positive predictive value of $81 \%$ (Table 5 ).

An MRE stricture risk score was derived from the multivariable analysis. Each patient was assigned 1 point for each of bowel dilatation $\geq 30 \mathrm{~mm}$, BWT $\geq 10 \mathrm{~mm}$, and stricture length $>5 \mathrm{~cm}$ (Table 5 and Figure 2). Subsequent surgery occurred in $81 \%$ for those with 3 points $(n=21), 55 \%$ with 2 points $(n=51), 35 \%$ with 1 point $(n=40)$ and $17 \%$ with no points $(n=24)(P<0.001)$. A Kaplan Meier survival analysis was performed with surgery as the endpoint; this 3-point score strongly predicted progression to surgery $(P<0.001)$ (Figure 3). Proportional hazard assumptions were met.

\section{DISCUSSION}

This study has identified specific MRE findings for patients with Crohn's disease strictures that are highly predictive of the disease course and the need for future surgery, adding to our understanding of the natural history of this common Crohn's disease complication. We have demonstrated that

This article is protected by copyright. All rights reserved. 
stricturing Crohn's disease is associated with a high morbidity, with almost half (46\%) of all patients having surgery, often within a few months of stricture diagnosis. Historic cohorts, with strictures identified using a variety of techniques and with variable follow-up, have reported a $50-70 \%$ surgical rate over 10 years. $(2,11)$

MRE is an accepted tool for the diagnosis of stricturing IBD and for quantifying the functional impact (proximal dilatation) as well as the degree of inflammation and possible fibrosis.(10) (12) Strictures are not clearly defined in European and American Guidelines for diagnostic imaging in Crohn's disease.

(13) (14) The definition often includes consistent luminal narrowing on all scan views, with or without proximal bowel dilatation. Our definition comprised consistent narrowing, 80 percent or more reduction in the luminal diameter, and bowel wall thickness $>3 \mathrm{~mm}$. Pre-stenotic bowel dilatation was not required in our study, as it varies in time and with oral intake. Nonetheless it was seen in nearly two thirds of patients in this study.

Our study shows that multiple MRE features are associated with an increased risk of surgery. The ability to predict the need for stricture surgery based on simple MRE characteristics (bowel wall thickness, stricture length and pre-stenotic dilatation) has great clinical value. When these three MRE characteristics are present, patients have a poor prognosis despite drug treatment and are likely to require surgery (PPV 81\%). This is clinically useful as this allows for closer monitoring of these patients and consideration of early surgical referral. Conversely, when none of these MRI features are present the prognosis is favourable with the majority of patients avoiding surgery (NPV 83\%). The value of this information in treatment decision making now needs to be tested prospectively.

Strictures usually comprise both fibrosis and active inflammation though differentiating between these may be difficult. $(15,16)$ ' (17) Our data suggest that features of active inflammation are commonly seen in strictures on MRE. These features include increased bowel wall thickness, ulceration, bowel wall oedema, DWI hyperintensity and an elevated MaRla score. CRP was also elevated in more than half of all patients requiring stricture surgery, adding support to the premise that untreated active inflammation may be as a precursor to surgery. Our study included, for the first time in patients with strictures, the MaRla score and DWI, both of which strongly predicted the occurrence of surgery.

In our cohort most patients were being treated with thiopurine and/or anti-TNF therapy at the time of stricture diagnosis. Overall this treatment did not impact on the risk of surgery. Rather than suggesting these drugs are ineffective in controlling inflammation or the development of strictures, it is possible that these medications were started too late, or have been used without therapeutic drug monitoring

This article is protected by copyright. All rights reserved. 
or optimisation. Our data suggest that anti-TNF therapy commenced at the time of stricture diagnosis decreases the need for surgery. This was significant on multivariable analysis, suggesting that anti-TNF therapy was effective even when accounting for possible confounders including stricture severity. This finding supports the conclusion of the CREOLE study in which introduction of anti-TNF therapy decreased symptoms and appeared to decrease the need for surgery.(3) However the CREOLE cohort had comparatively mild stricturing disease $(25 \%$ of patients had pre-stenotic dilatation versus $63 \%$ in our study). Other small retrospective cohorts have also suggest that surgery rates may be reduced in anti-TNF treated patients. $(4,18)$

In a recent study, Bossuyt et al developed the 'BACARDI' Risk Model for stratifying patients with Crohn's strictures.(11) This model included clinical, radiological and genetic risk factors. In this retrospective study many patients had conventional CT scans rather than MRE, precluding detailed cross-sectional stricture characterisation. The only imaging parameter used in the score was proximal bowel dilatation. In contrast, the three MRE parameters used in our current study were independent of clinical, biochemical or treatment factors but were more strongly associated with the outcome of surgery.

There are several limitations in our study. The study is retrospective and heterogeneous with regard to drug treatment and endoscopic therapy. MRE scans were read by a single radiologist, albeit blinded to the patients' clinical and treatment features. Furthermore inter-observer agreement between experienced MRI radiologists is excellent.(19) (20) The decision for stricture surgery in this cohort may have been influenced by the radiological findings, although the decision to operate was always made in the clinical context, with radiological findings being just one of the considerations. Further, the median time to stricture surgery after MRE was 6 months.

This study quantifies the risk of surgery using three simple MRE characteristics, and combines them in a risk score. This MRE surgical free survival risk score now requires validation in an independent cohort.

In conclusion, strictures represent a common and complex management problem in Crohn's disease. MRE appears to be a valuable tool for characterising strictures and identifying surgical risk. Anti-TNF therapy when commenced at stricture diagnosis may alter the natural history of this common complication. Knowledge of prognosis as well as the role of drug therapy may help inform treatment decisions for patients. 


\section{REFERENCES}

1. Henriksen M, Jahnsen J, Lygren I, Aadland E, Schulz T, Vatn MH, et al. Clinical course in Crohn's disease: results of a five-year population-based follow-up study (the IBSEN study). Scand J Gastroenterol. 2007;42(5):602-10.

2. Peyrin-Biroulet L, Loftus EV, Jr., Colombel JF, Sandborn WJ. The natural history of adult Crohn's disease in population-based cohorts. The American journal of gastroenterology. 2010;105(2):289-97.

3. Bouhnik Y, Carbonnel F, Laharie D, Stefanescu C, Hebuterne X, Abitbol V, et al. Efficacy of adalimumab in patients with Crohn's disease and symptomatic small bowel stricture: a multicentre, prospective, observational cohort (CREOLE) study. Gut. 2017.

4. Allocca M, Bonifacio C, Fiorino G, Spinelli A, Furfaro F, Balzarini L, et al. Efficacy of tumour necrosis factor antagonists in stricturing Crohn's disease: A tertiary center real-life experience. Dig Liver Dis. 2017;49(8):872-7.

5. Campos C, Perrey A, Lambert C, Pereira B, Goutte M, Dubois A, et al. Medical Therapies for Stricturing Crohn's Disease: Efficacy and Cross-Sectional Imaging Predictors of Therapeutic Failure. Dig Dis Sci. 2017;62(6):1628-36.

6. Panes J, Bouhnik Y, Reinisch W, Stoker J, Taylor SA, Baumgart DC, et al. Imaging techniques for assessment of inflammatory bowel disease: joint ECCO and ESGAR evidence-based consensus guidelines. Journal of Crohn's \& colitis. 2013;7(7):556-85.

7. Rieder F, Bettenworth D, Ma C, Parker CE, Williamson LA, Nelson SA, et al. An expert consensus to standardise definitions, diagnosis and treatment targets for anti-fibrotic stricture therapies in Crohn's disease. Aliment Pharmacol Ther. 2018;48(3):347-57.

8. Harris PA, Taylor R, Thielke R, Payne J, Gonzalez N, Conde JG. Research electronic data capture (REDCap)-A metadata-driven methodology and workflow process for providing translational research informatics support. Journal of Biomedical Informatics. 2009;42(2):377-81.

9. Satsangi J, Silverberg MS, Vermeire S, Colombel JF. The Montreal classification of inflammatory bowel disease: controversies, consensus, and implications. Gut. 2006;55(6):749.

10. Rimola J, Ordas I, Rodriguez S, Garcia-Bosch O, Aceituno M, Llach J, et al. Magnetic resonance imaging for evaluation of Crohn's disease: validation of parameters of severity and quantitative index of activity. Inflamm Bowel Dis. 2011;17(8):1759-68.

11. Bossuyt P, Debeuckelaere C, Ferrante M, de Buck van Overstraeten A, Vanbeckevoort D, Billiet $T$, et al. Risk Stratification for Surgery in Stricturing lleal Crohn's Disease: The BACARDI Risk Model. Journal of Crohn's \& colitis. 2018;12(1):32-8.

12. Rimola J, Planell N, Rodriguez S, Delgado S, Ordas I, Ramirez-Morros A, et al. Characterization of Inflammation and Fibrosis in Crohn/'s Disease Lesions by Magnetic Resonance Imaging. The American journal of gastroenterology. 2015;110(3):432-40.

13. Bruining DH, Zimmermann EM, Loftus EV, Jr., Sandborn WJ, Sauer CG, Strong SA, et al. Consensus Recommendations for Evaluation, Interpretation, and\&\#xa0;Utilization of Computed Tomography and Magnetic Resonance Enterography in Patients With Small Bowel

Crohn\&\#x2019;s\&\#xa0;Disease. Gastroenterology. 2018;154(4):1172-94.

14. Maaser C, Sturm A, Vavricka SR, Kucharzik T, Fiorino G, Annese V, et al. ECCO-ESGAR Guideline for Diagnostic Assessment in IBD Part 1: Initial diagnosis, monitoring of known IBD, detection of complications. Journal of Crohn's \& colitis. 2019;13(2):144-64.

15. Zappa M, Stefanescu C, Cazals-Hatem D, Bretagnol F, Deschamps L, Attar A, et al. Which magnetic resonance imaging findings accurately evaluate inflammation in small bowel Crohn's disease? A retrospective comparison with surgical pathologic analysis. Inflamm Bowel Dis. 2011;17(4):984-93.

16. Zhu J, Zhang F, Liu F, He W, Tian J, Han H, et al. Identifying the inflammatory and fibrotic bowel stricture: MRI diffusion-weighted imaging in Crohn's disease. Radiology of Infectious Diseases. 2015;2(3):128-33.

17. Gomollon F, Dignass A, Annese V, Tilg H, Van Assche G, Lindsay JO, et al. 3rd European Evidence-based Consensus on the Diagnosis and Management of Crohn's Disease 2016: Part 1: Diagnosis and Medical Management. Journal of Crohn's \& colitis. 2017;11(1):3-25. 
18. Pelletier AL, Kalisazan B, Wienckiewicz J, Bouarioua N, Soule JC. Infliximab treatment for symptomatic Crohn's disease strictures. Aliment Pharmacol Ther. 2009;29(3):279-85.

19. Tielbeek JA, Makanyanga JC, Bipat S, Pendse DA, Nio CY, Vos FM, et al. Grading Crohn disease activity with MRI: interobserver variability of MRI features, MRI scoring of severity, and correlation with Crohn disease endoscopic index of severity. AJR Am J Roentgenol. 2013;201(6):1220-8.

20. Ordas I, Rimola J, Alfaro I, Rodriguez S, Castro-Poceiro J, Ramirez-Morros A, et al. Development and Validation of a Simplified Magnetic Resonance Index of Activity for Crohn's disease.

Gastroenterology. 2019.

This article is protected by copyright. All rights reserved. 
Table 1. Patient cohort

\begin{tabular}{|c|c|c|}
\hline $\begin{array}{l}\text { Patient Characteristics } \\
\qquad(n=136)\end{array}$ & $\mathbf{n}$ & $\%$ \\
\hline$n$ (Male) & 61 & 45 \\
\hline Age, median (years) [IQR] & \multicolumn{2}{|c|}{$40[29-48]$} \\
\hline \multicolumn{3}{|l|}{ Smoking History $(n=94)$} \\
\hline Never & 45 & 48 \\
\hline Past & 15 & 16 \\
\hline Current & 34 & 36 \\
\hline \multicolumn{3}{|l|}{ Montreal Classification at Inclusion } \\
\hline \multicolumn{3}{|l|}{ Age at diagnosis (years): } \\
\hline$<16(\mathrm{~A} 1)$ & 35 & 26 \\
\hline $17-40(\mathrm{~A} 2)$ & 88 & 65 \\
\hline$>40$ (A3) & 13 & 10 \\
\hline \multicolumn{3}{|l|}{ Location } \\
\hline L1-Ileal & 58 & 43 \\
\hline L2-Colonic & 4 & 3 \\
\hline L3-Ileocolonic & 72 & 53 \\
\hline L4-Upper GI & 2 & 1 \\
\hline \multicolumn{3}{|l|}{ IBD Behaviour } \\
\hline B2-Stricturing & 114 & 84 \\
\hline B3-Penetrating & 22 & 16 \\
\hline \multicolumn{3}{|l|}{ Disease Modifier } \\
\hline UGI - disease & 6 & \\
\hline Perianal disease $(p)$ & 31 & \\
\hline \multicolumn{3}{|l|}{ Prior bowel resection (1 or more) } \\
\hline Yes & 91 & 67 \\
\hline No & 45 & 33 \\
\hline \multicolumn{3}{|c|}{$\begin{array}{l}\text { Hospitalization due to obstruction within } 3 \\
\text { months before or after MRE }\end{array}$} \\
\hline Yes & 39 & 29 \\
\hline No & 97 & 71 \\
\hline \multicolumn{3}{|l|}{ CRP (n=117) } \\
\hline$>10 \mathrm{mg} / \mathrm{L}$ & 44 & 38 \\
\hline$\leq 10 \mathrm{mg} / \mathrm{L}$ & 73 & 62 \\
\hline \multicolumn{3}{|c|}{ Concomitant drug(s) at the time of inclusion } \\
\hline 5-ASA & 15 & 11 \\
\hline Thiopurine & 75 & 55 \\
\hline Methotrexate & 17 & 13 \\
\hline Corticosteroids & 41 & 30 \\
\hline Anti-TNF & 38 & 28 \\
\hline No IBD drugs at baseline & 23 & 17 \\
\hline
\end{tabular}

This article is protected by copyright. All rights reserved. 
Table 2. Clinical characteristics associated with stricture surgery

\begin{tabular}{|c|c|c|c|c|c|c|c|}
\hline \multirow{2}{*}{ Category } & \multicolumn{2}{|c|}{ Stricture Surgery } & \multicolumn{2}{|c|}{ No Stricture Surgery } & \multirow[t]{2}{*}{ P Value } & \multirow{2}{*}{$\begin{array}{c}\text { Odds } \\
\text { Ratio } \\
\text { (OR) }\end{array}$} & \multirow[t]{2}{*}{$95 \% \mathrm{Cl}$} \\
\hline & n Patients & $\%$ & n Patients & $\%$ & & & \\
\hline n cases & 63 & 46 & 73 & 54 & & & \\
\hline Female & 39 & 62 & 36 & 49 & 0.14 & 0.60 & {$[0.30-1.19]$} \\
\hline Age (mean) & 38.7 & & 41 & & 0.32 & 0.99 & {$[0.96-1.01]$} \\
\hline Prior bowel resection & 36 & 56 & 55 & 75 & 0.03 & 0.44 & {$[0.21-0.91]$} \\
\hline \multicolumn{8}{|l|}{ Smoking History $(n=94)$} \\
\hline Never smoked & $21(n=44)$ & 48 & $24(n=50)$ & 48 & 0.98 & 1.01 & {$[0.45-2.27]$} \\
\hline Current smoker & $14(n=44)$ & 32 & $20(n=50)$ & 40 & 0.41 & 0.7 & {$[0.30-1.64]$} \\
\hline Elevated CRP >10mg/L (n=117) & $27(n=54)$ & 50 & $17(n=63)$ & 27 & 0.01 & 2.71 & {$[1.25-5.85]$} \\
\hline Hospitalization due to stricture & 23 & 37 & 16 & 22 & 0.06 & 2.05 & {$[0.96-4.36]$} \\
\hline \multicolumn{8}{|l|}{ Medications at stricture diagnosis } \\
\hline No drugs & 7 & 11 & 16 & 22 & 0.1 & 2.25 & {$[0.86-5.87]$} \\
\hline Corticosteroids & 19 & 30 & 22 & 30 & 0.94 & 1.03 & {$[0.49-2.15]$} \\
\hline Thiopurines & 37 & 59 & 38 & 52 & 0.44 & 1.31 & {$[0.66-2.59]$} \\
\hline Adalimumab & 11 & 17 & 18 & 25 & 0.29 & 0.64 & {$[0.27-1.48]$} \\
\hline Infliximab & 7 & 11 & 2 & 3 & 0.07 & 4.41 & [0.88-22.08] \\
\hline Anti-TNF & 18 & 29 & 20 & 27 & 0.88 & 1.06 & {$[0.50-2.25]$} \\
\hline Combination anti-TNF and thiopurine & 12 & 19 & 11 & 15 & 0.51 & 1.18 & {$[0.72-1.92]$} \\
\hline $\begin{array}{l}\text { Anti-TNF commenced following stricture } \\
\text { diagnosis }\end{array}$ & 3 & 5 & 11 & 15 & $0.061^{*}$ & 0.28 & {$[0.07-1.06]$} \\
\hline \multicolumn{8}{|l|}{ Endoscopy following MRE** $(n=51)$} \\
\hline Non-passable stricture (pre-dilatation) & $17(n=22)$ & 59 & $15(n=29)$ & 52 & 0.067 & 3.4 & [0.92-12.60] \\
\hline \multicolumn{8}{|l|}{ Endoscopic dilatation following MRE (n=32) } \\
\hline Non-passable following dilatation & $7(n=13)$ & 54 & $4(n=19)$ & 21 & 0.044 & 5.92 & [1.05-33.43] \\
\hline
\end{tabular}

*Using the chi-square test, $\mathrm{P}=\mathbf{0 . 0 4 9}$ for anti-TNF commenced following stricture diagnosis

**70 patients underwent endoscopy post MRE - stricture reached in 51 
Table 3. MRE characteristics associated with stricture surgery

\begin{tabular}{|c|c|c|c|c|c|c|c|c|}
\hline \multicolumn{9}{|c|}{ MRE features of 136 patients with Crohn's disease strictures } \\
\hline & $\begin{array}{l}\text { Total } \\
(\%) \text { or }\end{array}$ & \multicolumn{2}{|c|}{$\begin{array}{c}\text { Stricture } \\
\text { Surgery }(n=63)\end{array}$} & \multicolumn{2}{|c|}{$\begin{array}{c}\text { No stricture } \\
\text { Surgery }(n=73)\end{array}$} & \multirow[t]{2}{*}{ P Value } & \multirow{2}{*}{$\begin{array}{l}\text { Odds } \\
\text { Ratio } \\
\text { (OR) }\end{array}$} & \multirow[t]{2}{*}{$95 \% \mathrm{Cl}$} \\
\hline & [IQR] & $\begin{array}{c}\mathrm{n} \text { or } \\
\text { median }\end{array}$ & $\begin{array}{l}\text { \% or } \\
{[\mathrm{IQR}]}\end{array}$ & $\begin{array}{c}\mathrm{n} \text { or } \\
\text { median }\end{array}$ & $\begin{array}{l}\text { \% or } \\
{[\text { IQR] }}\end{array}$ & & & \\
\hline Maximum wall thickness (mm) & 9 [7-12] & 9 & {$[8-11]$} & 8 & [7-9] & 0.001 & 1.31 & {$[1.12-1.55]$} \\
\hline Thickness $\geq 10 \mathrm{~mm}$ & $48(35 \%)$ & 30 & 48 & 18 & 25 & 0.006 & 2.78 & {$[1.34-5.74]$} \\
\hline More than one stricture & $59(43 \%)$ & 33 & 52 & 26 & 36 & 0.05 & 1.98 & {$[1.00-3.96]$} \\
\hline \multicolumn{9}{|l|}{ Stricture location } \\
\hline Ileocolic anastomosis & $48(35 \%)$ & 14 & 22 & 27 & 37 & 0.06 & 0.49 & {$[0.23-1.04]$} \\
\hline Colonic & $20(15 \%)$ & 10 & 16 & 4 & 5 & 0.06 & 3.25 & {$[0.97-10.95]$} \\
\hline Terminal ileum/ileum & $73(54 \%)$ & 38 & 60 & 35 & 48 & 0.15 & 1.65 & {$[0.83-3.27]$} \\
\hline Dominant stricture length (mm) & $60[35-130]$ & 80 & {$[45-170]$} & 50 & $\begin{array}{l}{[30-} \\
100]\end{array}$ & 0.003 & 1.01 & {$[1.00-1.01]$} \\
\hline Length $>5 \mathrm{~cm}$ & $72(53 \%)$ & 43 & 68 & 29 & 40 & 0.001 & 3.26 & {$[1.61-6.62]$} \\
\hline Sum of all stricture lengths (mm) & $100[50-200]$ & 120 & {$[70-200]$} & 75 & $\begin{array}{l}{[40-} \\
150]\end{array}$ & 0.005 & 1.00 & {$[1.001-1.008]$} \\
\hline Proximal luminal diameter (mm) & $31.5[27-38]$ & 34 & [30-41] & 30 & {$[26-36]$} & 0.01 & 1.04 & {$[1.01-1.08]$} \\
\hline Proximal luminal diameter $\geq 30 \mathrm{~mm}$ & $85(63 \%)$ & 48 & 76 & 37 & 51 & 0.003 & 3.11 & {$[1.49-6.52]$} \\
\hline $\begin{array}{l}\text { Luminal Diameter of Narrowed } \\
\text { Segment }(\mathrm{mm})\end{array}$ & $3[2-4]$ & 2 & {$[2-3]$} & 3 & {$[2-5]$} & 0.06 & 0.84 & {$[0.70-1.01]$} \\
\hline $\begin{array}{l}\text { Luminal Diameter of Narrowed } \\
\text { Segment } \leq 2 \mathrm{~mm}\end{array}$ & $58(43 \%)$ & 34 & 54 & 24 & 33 & 0.01 & 0.42 & {$[0.21-0.84]$} \\
\hline \multicolumn{6}{|l|}{$\begin{array}{l}\text { Delayed Enhancement of Stricture } \\
(n=133)\end{array}$} & & & \\
\hline None & $4(3 \%)$ & 1 & 2 & 3 & 4 & & & \\
\hline Mild to moderate & 125 (94\%) & 59 & 94 & 66 & 90 & & & \\
\hline Severe & $4(3 \%)$ & 2 & 3 & 2 & 3 & 0.48 & 1.67 & {$[0.40-7.01]$} \\
\hline \multirow{2}{*}{\multicolumn{9}{|c|}{$\begin{array}{l}\text { Type of Delayed Enhancement of } \\
\text { Stricture }(n=129) \\
\text { Laminar }\end{array}$}} \\
\hline & & & & & & & & \\
\hline Transmural & 47 (35\%) & 22 & 35 & 25 & 34 & 0.93 & 0.97 & {$[0.47-1.99]$} \\
\hline Oedema associated with stricture & $56(41 \%)$ & 35 & 56 & 21 & 29 & 0.002 & 3.10 & {$[1.52-6.29]$} \\
\hline Stricture Ulceration & $58(43 \%)$ & 32 & 51 & 26 & 36 & 0.08 & 1.87 & {$[0.94-3.71]$} \\
\hline $\begin{array}{l}\text { Inflammatory change of } \\
\text { mesenteric fat }\end{array}$ & $62(46 \%)$ & 38 & 60 & 24 & 33 & 0.002 & 3.10 & {$[1.54-6.26]$} \\
\hline \multicolumn{9}{|l|}{ DWI hyperintensity $(n=135)$} \\
\hline Absent & $21(16 \%)$ & 5 & 8 & 16 & 22 & & & \\
\hline Elevated less than lymph nodes & $91(67 \%)$ & 42 & 67 & 49 & 67 & & & \\
\hline Elevated more than lymph nodes & $23(17 \%)$ & 16 & 25 & 7 & 10 & 0.003 & 2.70 & [1.39-5.26] \\
\hline Fistula in association with stricture & $20(15 \%)$ & 14 & 22 & 6 & 8 & 0.027 & 3.19 & {$[1.14-8.89]$} \\
\hline Abscess / phlegmon associated & $23(17 \%)$ & 13 & 21 & 10 & 14 & 0.29 & 1.64 & {$[0.66-4.05]$} \\
\hline $\begin{array}{l}\text { Mesenteric lymphadenopathy } \\
>1 \mathrm{~cm}\end{array}$ & $27(20 \%)$ & 13 & 21 & 14 & 19 & 0.83 & 1.10 & [0.47-2.55] \\
\hline $\begin{array}{l}\text { Relative contrast enhancement } \\
(\%)(n=128)\end{array}$ & 132 [93-181] & 136 & [96-184] & 124 & $\begin{array}{l}90- \\
177]\end{array}$ & 0.52 & 1.00 & [0.996-1.008] \\
\hline $\begin{array}{l}\text { MaRla score for dominant } \\
\text { stricture }(n=128)\end{array}$ & 21.8 [14.8-30.9] & 28.1 & $\begin{array}{l}{[17.1-} \\
32.7]\end{array}$ & 17.6 & $\begin{array}{l}{[13.6-} \\
28.2]\end{array}$ & $<0.001$ & 1.08 & [1.04-1.13] \\
\hline $\begin{array}{l}\text { MaRla score for dominant } \\
\text { stricture }>11(n=128)\end{array}$ & $123(96 \%)$ & 58 & 92 & 65 & 89 & 0.26 & 3.57 & [0.39-32.85] \\
\hline $\begin{array}{l}\text { MaRla score for dominant } \\
\text { stricture }>24(n=128)\end{array}$ & $59(46 \%)$ & 37 & 59 & 22 & 30 & 0.001 & 3.59 & [1.73-7.47] \\
\hline
\end{tabular}


Table 4. Stricture location for total of 235 small and large bowel strictures

\begin{tabular}{|l|c|c|c|c|}
\hline Location & $\begin{array}{c}\text { Location of } \\
\text { Dominant Stricture }\end{array}$ & \% & Location of all Strictures* & $\%$ \\
\hline Duodenal & 0 & 0 & 0 & 0 \\
\hline Jejunal & 4 & 3 & 9 & 5 \\
\hline $\begin{array}{l}\text { lleum (not within 10cm of } \\
\text { ileo-cecal valve) }\end{array}$ & 25 & 18 & 29 & 17 \\
\hline $\begin{array}{l}\text { Terminal Ileum (within 10cm } \\
\text { ileo-cecal valve) }\end{array}$ & 48 & 35 & 58 & 35 \\
\hline $\begin{array}{l}\text { Ileocolic Anastomosis } \\
\text { Anastomosis Other }\end{array}$ & 41 & 30 & 48 & 29 \\
\hline Colon & 14 & 3 & 4 & 12 \\
\hline Total & 136 & 10 & 20 & 168 \\
\hline
\end{tabular}

*Note: more than one stricture could be seen in the one location 
Table 5. Multivariable analysis of MRE and clinical characteristics associated with surgery and sensitivity/specificity analysis

\begin{tabular}{|c|c|c|c|c|c|c|c|c|c|}
\hline & $\begin{array}{l}\text { Odds } \\
\text { Ratio } \\
\text { (OR) }\end{array}$ & $95 \% \mathrm{Cl}$ & $\begin{array}{c}P \\
\text { Value }\end{array}$ & $\begin{array}{c}\text { Sens- } \\
\text { tivity } \\
(\%)\end{array}$ & $\begin{array}{c}\text { Spec- } \\
\text { ificity } \\
(\%)\end{array}$ & $\begin{array}{c}\text { Positive } \\
\text { Predictive } \\
\text { Value (\%) }\end{array}$ & $\begin{array}{l}\text { Negative } \\
\text { Predictive } \\
\text { Value (\%) }\end{array}$ & $\begin{array}{l}\text { Area } \\
\text { Under } \\
\text { the } \\
\text { Curve } \\
\text { (AUC)* }\end{array}$ & $\begin{array}{c}\text { Points, } \\
\mathrm{n}\end{array}$ \\
\hline \multicolumn{10}{|c|}{ MRE Characteristics } \\
\hline $\begin{array}{l}\text { Proximal luminal diameter } \\
\geq 30 \mathrm{~mm}\end{array}$ & 2.98 & {$[1.36-6.55]$} & 0.01 & 76.2 & 49.3 & 56.5 & 70.6 & 0.67 & 1 \\
\hline $\begin{array}{l}\text { Bowel wall thickness } \geq 10 \mathrm{~mm} \text { at } \\
\text { stricture }\end{array}$ & 2.42 & {$[1.11-5.27]$} & 0.008 & 47.6 & 75.3 & 62.5 & 62.5 & 0.67 & 1 \\
\hline Stricture length $>5 \mathrm{~cm}$ & 2.56 & [1.21-5.43] & 0.02 & 68.3 & 60.3 & 59.7 & 68.8 & 0.68 & 1 \\
\hline MRE Combined AUC & & & & & & & & 0.76 & \\
\hline \multicolumn{10}{|c|}{ Clinical Features } \\
\hline $\begin{array}{l}\text { Hospitalization due to bowel } \\
\text { obstruction }\end{array}$ & 2.50 & {$[1.06-5.90]$} & 0.04 & 36.5 & 78.1 & 59 & 58.8 & & \\
\hline $\begin{array}{l}\text { MRE and Clinical Features } \\
\text { Combined AUC }\end{array}$ & & & & & & & & 0.78 & \\
\hline \multicolumn{10}{|c|}{ Number of MRE Stricture Characteristics ( $n$ ) } \\
\hline$n \geq 1$ & & & & 93.7 & 27.4 & 52.7 & 83.3 & & \\
\hline$n \geq 2$ & & & & 71.4 & 63.0 & 62.5 & 62.2 & & \\
\hline $\mathrm{n}=3$ & & & & 27.0 & 94.5 & 81.0 & 60.0 & & \\
\hline
\end{tabular}

${ }^{*}$ AUC analysis performed using continuous MRE measurements 
Figure 1. Schematic presentation of the data collection

* exclusion due to incomplete history, <12 months follow up (if no surgery) and no confirmed diagnosis of Crohn's disease

\section{Figure 2.}

Example MRE image

A coronal HASTE in a 38 year old male. The stricture (ring) is $12 \mathrm{~cm}$ long, with mural thickening (shown) to $9 \mathrm{~mm}$ and pre-stenotic distension to $32 \mathrm{~mm}$ (double arrow). A pseudodiverticulum is present projecting towards the bladder (small arrow).

\section{Figure 3.}

Surgical free survival based on 3 MRE stricture characteristics 




JGH_14908_Figure1.JPG 


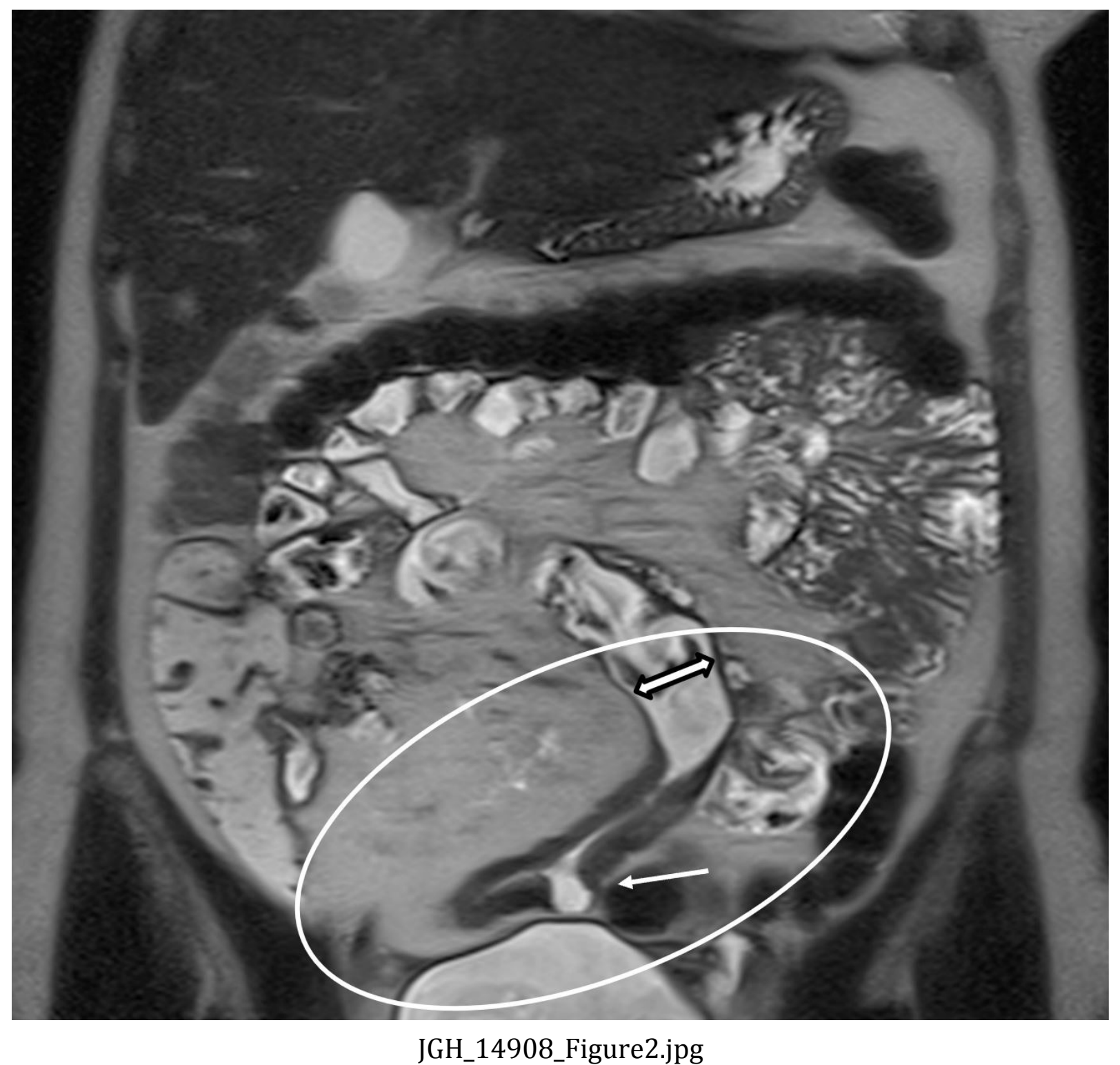

This article is protected by copyright. All rights reserved. 


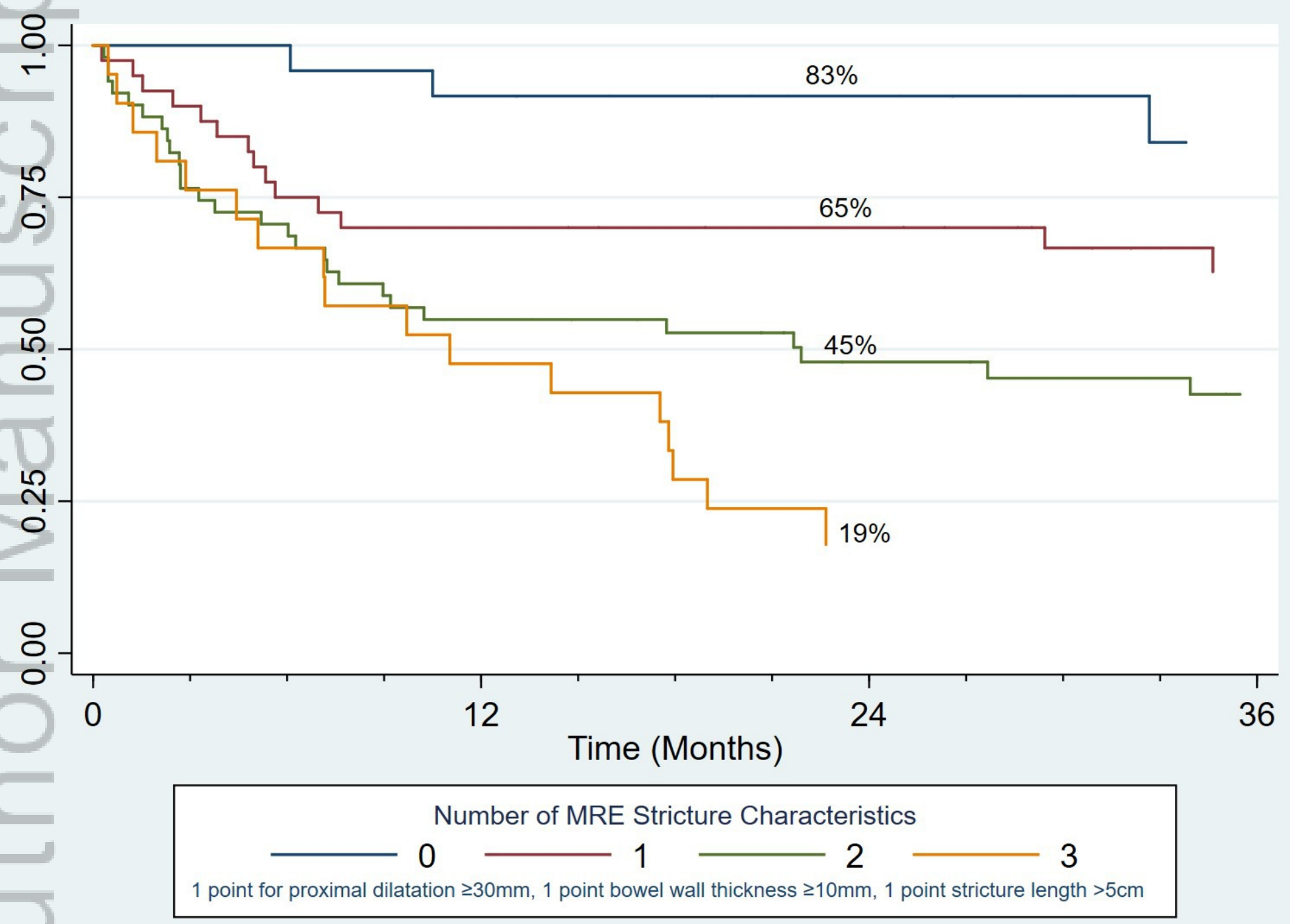

JGH_14908_Figure3.jpg

This article is protected by copyright. All rights reserved. 


\section{University Library}

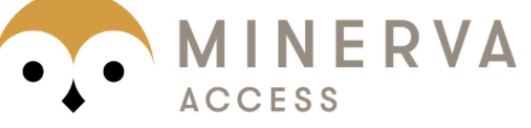

A gateway to Melbourne's research publications

Minerva Access is the Institutional Repository of The University of Melbourne

Author/s:

Schulberg, JD;Wright, EK;Holt, BA;Sutherland, TR;Hume, SJ;Hamilton, AL;Ross, AL;Connell, WC;Brown, SJ;Lust, M;Miller, AM;Bell, SJ;Kamm, MA

Title:

Magnetic resonance enterography for predicting the clinical course of Crohn's disease strictures

Date:

2019-11-11

Citation:

Schulberg, J. D., Wright, E. K., Holt, B. A., Sutherland, T. R., Hume, S. J., Hamilton, A. L., Ross, A. L., Connell, W. C., Brown, S. J., Lust, M., Miller, A. M., Bell, S. J. \& Kamm, M. A. (2019). Magnetic resonance enterography for predicting the clinical course of Crohn's disease strictures. JOURNAL OF GASTROENTEROLOGY AND HEPATOLOGY, 35 (6), pp.980-987. https://doi.org/10.1111/jgh.14908.

Persistent Link:

http://hdl.handle.net/11343/286596 